\title{
Individuals with Restless Legs Syndrome Tend to have Severe Depressive Symptoms: Findings from a Community-Based Cohort Study
}

\author{
Chul-Hyun Cho ${ }^{1,2}$, Leen $\mathrm{Kim}^{1,2}$, and Heon-Jeong Lee ${ }^{1,2} \bowtie$ \\ ${ }^{1}$ Department of Psychiatry, Korea University College of Medicine, Seoul, Republic of Korea \\ ${ }^{2}$ Sleep-Wake Disorders Center, Korea University Anam Hospital, Seoul, Republic of Korea
}

\begin{abstract}
Restless legs syndrome (RLS) is a sensorimotor neurological disturbance causing physical and psychological distress. Here, we investigated the severity and effect of depressive symptoms in RLS among a Korean cohort population. Depressive symptoms were more prevalent in the RLS group than in the non-RLS group [ $\geq$ mild depression: odds ratio $(\mathrm{OR})=1.95, \mathrm{p}<0.001 ; \geq$ moderate depression: $\mathrm{OR}=6.15$, $\mathrm{p}<0.001$; and $\geq$ severe depression: $\mathrm{OR}=56.54, \mathrm{p}<0.001$ ], with a predominant proportion of severe depression (97\%) in the RLS group. We found that difficulty falling asleep $(O R=8.16, p<0.001)$, broken sleep $(O R=11.66, p=0.001)$, early morning awakening $(O R=8.5, p<0.001)$, and excessive daytime sleepiness $(\mathrm{OR}=3.04, \mathrm{p}=0.031)$ were significantly frequent in individuals with severe depression in the RLS group. Red blood cell count was significantly low in individuals with severe depression in the RLS group ( $\mathrm{p}=0.041)$. We found that severe depression was associated with RLS, suggesting the evaluation and management of mood symptoms and sleep-related and hematological features when treating RLS.

Psychiatry Investig 2017;14(6):887-893
\end{abstract}

Key Words Restless legs syndrome, Depressive symptom, Insomnia, Daytime sleepiness, Hematological features.

\section{INTRODUCTION}

Restless legs syndrome (RLS) is a sensorimotor neurological disturbance characterized by an unpleasant sensation in and urge to move the legs at night. ${ }^{1}$ Several epidemiological studies have reported the prevalence of RLS in South Korea between $7.5 \%$ and $12.1 \%{ }^{2,3}$ The essential diagnostic criteria for RLS suggested by the International Restless Legs Syndrome Study Group (IRLSSG) are 1) desire to move the limbs, usually associated with paresthesias/dysesthesias; 2) motor restlessness; 3) symptoms worse or exclusively present at rest (lying or sitting) with at least partial and temporary relief by activity; and 4) symptoms worse in the evening or at night. ${ }^{4}$ Although the pathophysiology of RLS is not sufficiently established, dysfunction in dopamine metabolism is proposed as a

Received: February 5, 2017 Revised: April 6, 2017

Accepted: April 9, 2017 Available online: October 17, 2017

$\triangle$ Correspondence: Heon-Jeong Lee, MD, PhD

Department of Psychiatry, Korea University Anam Hospital, 73 Inchon-ro, Seongbuk-gu, Seoul 02841, Republic of Korea

Tel: +82-2-920-5815, Fax: +82-2-929-7679, E-mail: leehjeong@korea.ac.kr

(a) This is an Open Access article distributed under the terms of the Creative Commons Attribution Non-Commercial License (http://creativecommons.org/licenses/by$\mathrm{nc} / 4.0$ ) which permits unrestricted non-commercial use, distribution, and reproduction in any medium, provided the original work is properly cited. probable contributory factor. ${ }^{5}$ Furthermore, several studies have reported the importance of genetic factors in RLS. ${ }^{6-8}$ Hematological features such as anemia are also related with RLS. ${ }^{9,10}$ In particular, iron deficiency anemia (IDA) has been suggested as a major cause of RLS because cellular insufficiency of iron in the central nervous system decreases the activity of tyrosine hydroxylase resulting in RLS symptoms. ${ }^{11,12}$ Prior studies reported that patients with IDA showed a very high RLS prevalence of about $40 \% .{ }^{10,13}$ Testing the serum ferritin level is recommended in the process of RLS diagnosis. Moreover, there are various studies on the association between RLS and hematological features including polycythemia vera, ${ }^{14} \mathrm{mul}-$ tiple myeloma, ${ }^{15}$ and blood donors. ${ }^{16}$

Although RLS symptoms do not cause life-threatening consequences, chronic clinical RLS symptoms might have a persistant influence on the patient's daily life. ${ }^{17,18}$ Apart from sleep disturbances such as difficulties in falling asleep and frequent awakenings, patients with RLS experience a poor quality of life due to various other problems caused by RLS. Psychological discomfort followed by RLS is considered as a serious problem in patients with RLS. RLS symptoms cause psychological distress either directly or indirectly, and lead to psychiatric illnesses and decreased well-being. ${ }^{19}$ 
Several studies have shown the association between RLS and mood disorders, especially between RLS and depressive disorders. A 2- to 4-fold risk of depressive disorder in patients with RLS compared with healthy controls was reported in epidemiological studies. ${ }^{20}$ Winkelman et al. ${ }^{21}$ reported a positive correlation between RLS symptom frequency and depression severity. Moreover, patients with RLS had significantly higher 12-month rates of major depression, panic disorder, or generalized anxiety disorder than controls. ${ }^{22}$ Various depression rating scales have been used to investigate the association between RLS and depression including the Hamilton Anxiety and Depression Scale, ${ }^{19}$ the Center for Epidemiologic Studies Depression Scale (CES-D), ${ }^{23}$ the Zung SelfRating Depression, ${ }^{21}$ and the Beck Depression Inventory (BDI). ${ }^{24}$ Most studies, regardless of the type of method or scale used, consistently reported a high correlation between depression and RLS. Depression and RLS are frequently comorbid, and depressive mood symptoms may have an effect on RLS and related features, such as clinical features, course, treatment, and outcome. ${ }^{20}$ In the previous study performed on the same Korea cohort population as this present study, depressive mood was correlated with RLS. ${ }^{25}$ However, that study focused on the association between RLS and irritable bowel syndrome. For a more in-depth discussion, it will be important to analyze the characteristic severity of depression in the RLS group and evaluate the clinical features of patients with RLS comorbid with depressive symptoms.

Here, we investigated the severity and effect of depressive mood symptoms in RLS among the Korean cohort population. We investigated the presence and severity of depressive symptoms in patients with RLS by comparing them with those of non-RLS controls. In addition, we analyzed the characteristics of patients with RLS and severe depressive symptoms compared with those without severe depressive symptoms.

\section{METHODS}

\section{Study population}

Subjects for the present study were from the Ansung and Ansan cohorts of the Korea Association Resource (KARE) project, and these cohorts were investigated as part of the Korea Genome Epidemiology Study (KoGES). A total of 7,515 participants ranging in age from 40 to 69 years were enrolled in the cohort. Various epidemiological and health-related information, more than 260 traits, were collected for the cohort study, such as demographic information, medical and family disease histories, health condition, lifestyle, mood state, and sleep-related symptoms. ${ }^{26}$ In the process of establishing the KoGES, written informed consent and ethics committee approval had been previously obtained for the cohort study. ${ }^{27}$
Approval from the Institutional Review Board (IRB No. IEC107014) of Korea University was obtained for the use and analysis of the cohort data.

\section{Assessment}

Subjects were asked 4 RLS-related questions based on the following criteria: 1) an urge to move the legs, usually accompanied or caused by uncomfortable and unpleasant sensations in the legs, 2) the urge to move or unpleasant sensations beginning or worsening during periods of rest or inactivity such as lying or sitting, 3) the urge to move or unpleasant sensations are partially or completely relieved by movement, such as walking or stretching, at least as long as the activity continues, and 4) the urge to move or unpleasant sensations are worse during the evening or night than during the day or only occur in the evening or night. ${ }^{1}$ Responders to the RLS symptom questions were divided into the RLS group and non-RLS group according to the answer to the 4 questions. Subjects who answered "yes" to all the 4 questionnaire items were categorized into the RLS group, whereas subjects who answered "no" to all the 4 questionnaire items were categorized into the non-RLS group. Other subjects who answered "yes" to only 1 to 3 questionnaire items were excluded from the analysis. Finally, there were 142 subjects in the RLS group and 2,884 subjects in the non-RLS group in the present study.

Depressive mood symptoms of subjects were investigated using the Korean version of BDI, which is used for the assessment of depressive mood symptoms. ${ }^{28,29}$ The severity of depressive mood symptoms was classified according to the total score of BDI; the total score of 10-15 indicates mild depressive mood, 16-23 indicates moderate depressive mood, and 2463 indicates severe depressive mood symptoms. We used each cutoff value for the analysis of depressive mood symptoms in RLS.

Insomnia problems were evaluated based on the following 3 types of symptoms: difficulty falling asleep, broken sleep, and early morning awakening. Several aspects of sleep-wake cycle-related problems were evaluated including nap and shift work. Moreover, Epworth sleepiness scale (ESS) was used to evaluate daytime sleepiness. ${ }^{30}$ The total ESS score obtained was used to classify excessive daytime sleepiness state with a score of 10 points or more.

Laboratory test results of red blood cell (RBC) count, hemoglobin $(\mathrm{Hb})$ levels, and hematocrit (Hct) levels were obtained from the cohort data, and we classified anemia based on the Reference Values for Laboratory Tests in the textbook of Internal Medicine. ${ }^{31}$

\section{Statistical analysis}

Statistical analysis was performed using SPSS software, 
version 21.0 (IBM Corp., Armonk, NY, USA). We analyzed whether there were significant differences in sex, age, and depressive mood symptoms between the RLS and non-RLS groups. We evaluated the effect of depressive mood symptoms on sleep-related symptoms and hematological features within the RLS group. Chi-square test ( $\chi^{2}$ test) or Fisher's exact test was performed on categorical variables to evaluate association, and Student's t-test was performed on continuous variables to evaluate the difference between the groups. The statistical significance was set at $\mathrm{p}<0.05$.

\section{RESULTS}

The prevalence of female subjects in the RLS group (80; $56.3 \%)$ was higher than that in the non-RLS group $(1,298$; $45.0 \%)$ [odds ratio $(\mathrm{OR})=1.577, \mathrm{p}=0.008$ ]. The mean age of the RLS group ( $54.13 \pm 8.18$ years; mean $\pm S D$ ) was significantly higher than that of the non-RLS group (52.47 \pm 7.51 years) $(\mathrm{p}=0.011)$. Furthermore, the total BDI score was significantly higher in the RLS group than in the non-RLS group (RLS vs. non-RLS; $15.36 \pm 14.29$ vs. $7.37 \pm 6.03, \mathrm{p}<0.001)$. For further evaluation, we analyzed the depressive mood by severity according to the standardized cutoffs as mentioned earlier, between the two groups.

We analyzed the prevalence of depressive symptoms within the 2 groups based on mild (BDI score $\geq 10$ ), moderate (BDI score $\geq 16$ ), and severe depression (BDI score $\geq 24$ ) cutoffs of
BDI. There were 78 subjects without depression (54.89\%), 2 subjects with mild depression (1.41\%), no subjects with moderate depression (0\%), and 62 subjects with severe depression (43.7\%) in RLS group ( $\mathrm{n}=142$ ), and 2,031 subjects without depression (70.35\%), 530 subjects with mild depression (18.4\%), 284 subjects with moderate depression (9.85\%), and 39 subjects with severe depression in non-RLS group $(n=2,884)$. Depressive mood symptoms were found to be more prevalent in the RLS group than in the non-RLS group based on the 3 different severity cutoffs of BDI score ( $\geq$ mild depression: $\mathrm{OR}=$ $1.95, \mathrm{p}<0.001 ; \geq$ moderate depression $\mathrm{OR}=6.15, \mathrm{p}<0.001$; and $\geq$ severe depression: $\mathrm{OR}=56.54, \mathrm{p}<0.001$ ) (Figure 1). Moreover, the prevalence of severe depression was predominantly higher than that of mild or moderate depression in the RLS group, whereas the prevalence of depression in the non-RLS group reduced sequentially depending on its severity. Interestingly, $97 \%$ of the subjects who reported depressive mood symptoms showed severe depression according to the BDI score within the RLS group.

To evaluate the effect of severe depressive mood symptoms on RLS, we analyzed sleep-related and hematological features only in subjects with RLS by dividing them into 2 subgroups, the severe depression group (BDI score $\geq 24$ ) and group without severe depression (BDI score <24) (Table 1). We found that difficulty falling asleep (severe depression vs. non-severe depression; $61.3 \%$ vs. $16.3 \%, \mathrm{OR}=8.16, \mathrm{p}<0.001$ ), broken sleep (69.4\% vs. $16.3 \%, \mathrm{OR}=11.66, \mathrm{p}=0.001)$, and early morning

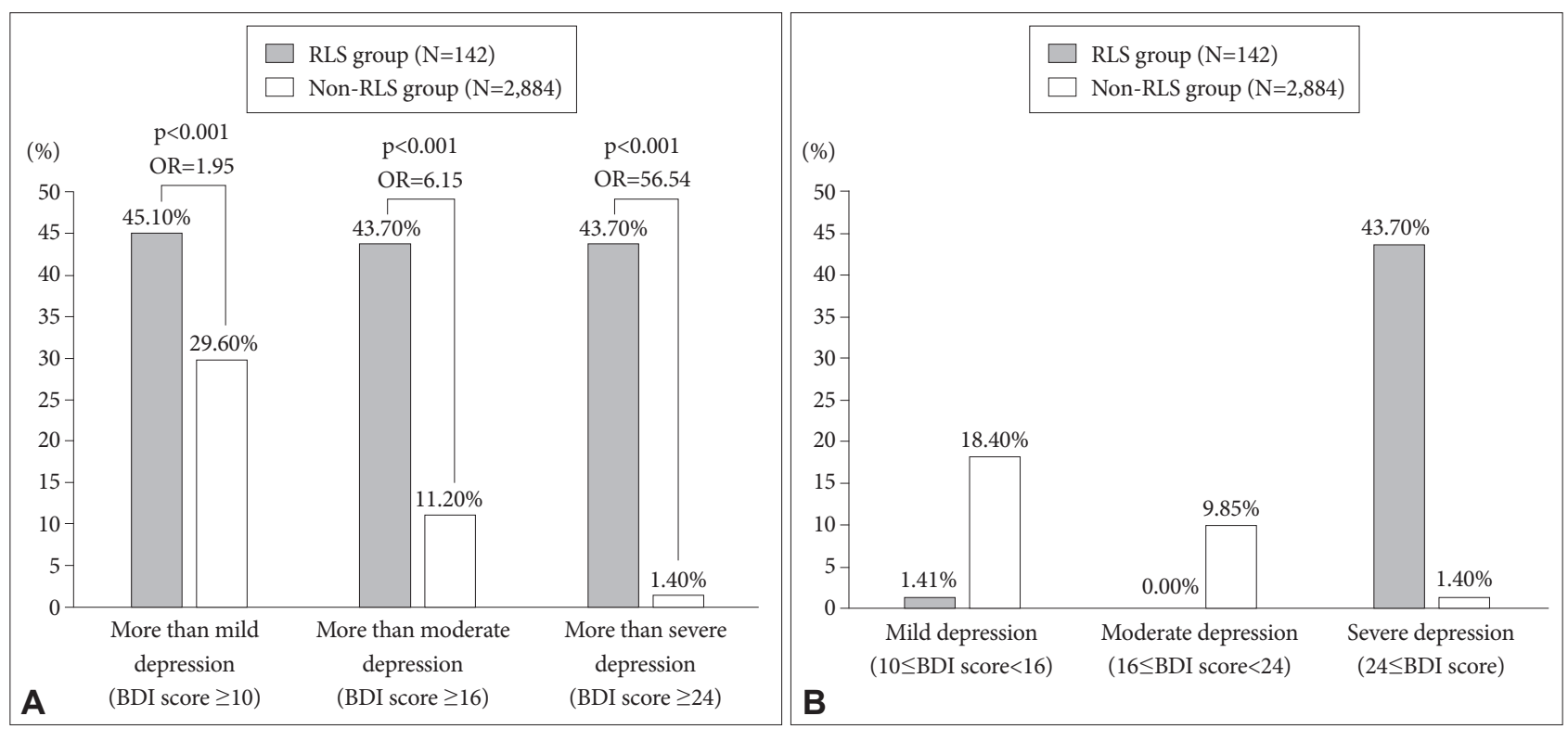

Figure 1. Prevalence of depressive mood symptoms based on the severity according to Beck Depression Inventory (BDI) score between restless legs syndrome (RLS) and non-RLS groups. A: Graphical representation of the prevalence of depressive mood symptoms according to the $\mathrm{BDI}$ score between groups. The prevalence indicates accumulated prevalence over cutoff of the BDI score for mild (10 $\leq \mathrm{BDI}$ score),

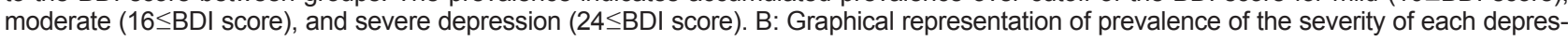
sive mood symptom among the groups: Mild depression $(10 \leq \mathrm{BDI}$ score $<16)$, moderate depression (16 $\leq \mathrm{BDI}$ score<24), and severe depression $(24 \leq \mathrm{BDI}$ score). 
Table 1. Sleep-related and hematological features of subjects with severe depressive mood symptoms in the restless legs syndrome group

\begin{tabular}{|c|c|c|c|c|}
\hline $\begin{array}{c}\text { Sleep-related and } \\
\text { hematological features }\end{array}$ & $\begin{array}{l}\text { Subjects with severe depression } \\
\qquad(\mathrm{N}=62) \\
\text { Mean } \pm \text { SD or } \mathrm{N}(\%)\end{array}$ & $\begin{array}{l}\text { Subjects without severe depression } \\
\qquad(\mathrm{N}=80) \\
\text { Mean } \pm \mathrm{SD} \text { or } \mathrm{N}(\%)\end{array}$ & OR & $\mathrm{p}$-value \\
\hline \multicolumn{5}{|l|}{ Insomnia problems } \\
\hline Difficulty falling asleep* & $38(61.3)$ & $13(16.3)$ & 8.16 & $<0.001$ \\
\hline Broken sleep* & $43(69.4)$ & $13(16.3)$ & 11.66 & 0.001 \\
\hline Early morning awakening* & $34(54.8)$ & $10(12.5)$ & 8.5 & $<0.001$ \\
\hline \multicolumn{5}{|l|}{ Sleep-wake cycle related problems } \\
\hline Nap during daytime* & $29(46.8)$ & $40(50)$ & 0.88 & 0.737 \\
\hline Shift worker* & $8(12.9)$ & $0(0)$ & 0.4 & 0.001 \\
\hline \multicolumn{5}{|l|}{ Daytime sleepiness } \\
\hline ESS total score & $6.77 \pm 4.21$ & $4.95 \pm 3.07$ & - & 0.005 \\
\hline ESS score $\geq 10^{\dagger}$ & $14(22.6)$ & $7(8.8)$ & 3.04 & 0.031 \\
\hline \multicolumn{5}{|l|}{ Hematological features } \\
\hline Red Blood Cell count & $4.32 \pm 0.42$ & $4.48 \pm 0.5$ & - & 0.041 \\
\hline Hemoglobin & $13.53 \pm 1.54$ & $14.01 \pm 1.53$ & - & 0.067 \\
\hline Hematocrit & $40.71 \pm 4.34$ & $41.61 \pm 4.16$ & - & 0.211 \\
\hline Anemia* & $9(14.5)$ & $7(8.8)$ & 1.77 & 0.298 \\
\hline
\end{tabular}

Student's t-test was performed on continuous variables except for chi-square test $\left(\chi^{2}\right.$ test $)$ or Fisher's exact test. p $<0.05 .{ }^{*}$ chi-square test $\left(\chi^{2}\right.$ test), ${ }^{\dagger}$ Fisher's exact test. ESS: Epworth sleepiness scale, SD: standard deviation, OR: odds ratio

awakening ( $54.8 \%$ vs. $12.5 \%, \mathrm{OR}=8.5, \mathrm{p}<0.001)$ were significantly frequent in the severe depression subgroup. This showed the high risk of insomnia when RLS was comorbid with severe depression. Nap during daytime $(\mathrm{OR}=0.88, \mathrm{p}=0.737)$ was not significantly different; 8 shift workers had severe depression whereas individuals who were not shift workers were founded in group without severe depression $(\mathrm{OR}=0.4, \mathrm{p}=0.001)$. The total ESS score in severe depression subgroup was significantly higher than that in subgroup without severe depression (severe depression vs. non-severe depression; $6.77 \pm 4.21$ vs. $4.95 \pm 3.07$, $\mathrm{p}=0.005$ ). Excessive daytime sleepiness (ESS score $\geq 10$ ) was significantly frequent in the severe depression subgroup (severe depression vs. non-severe depression; $22.6 \%$ vs. $8.8 \%$, OR= $3.04, \mathrm{p}=0.031$ ) within the RLS group. Among hematological features, only RBC count showed a significantly lower level in the severe depression subgroup than in the subgroup without severe depression ( $4.32 \pm 0.42$ vs. $4.48 \pm 0.5, \mathrm{p}=0.041)$. However, $\mathrm{Hb}(\mathrm{p}=0.067)$, Hct $(\mathrm{p}=0.211)$, and anemia levels $(\mathrm{p}=0.298)$ did not show any significant differences between the subgroups.

\section{DISCUSSION}

Depressive mood was found to be significantly more severe and frequent in the RLS group than in the non-RLS group. This result is in line with previous findings that RLS is closely related to psychiatric problems, including depression. Previous studies have reported a close association between RLS and depression, and it is presumed that depression is due to direct or indirect effects of RLS, although no clear cause is known. ${ }^{20,22}$ In interpreting the results of this study, secondary RLS or RLS due to medication, including antidepressants, should be considered. ${ }^{32,33}$ However, because of the limited data in the present study, sufficient and careful consideration was difficult. Nonetheless, it is possible that the most important cause of depression is that RLS symptoms induce insomnia. ${ }^{34}$ In this study, severe depression, according to the BDI score, was predominantly frequent only in the RLS group with very high risk. This is interesting because of not only high BDI score and depression prevalence but also the high predominance of severe depression in the RLS group. In the previous study, only the relationship between RLS and depressive symptoms was analyzed; however, no correlation between depression severity and RLS was reported. ${ }^{9,12,25}$ In the present study, we found that among the patients with depression (based on BDI scores) in the RLS group, $97 \%$ of them had severe depression. This result, for the first time, indicates that severe depression is overwhelmingly frequent in patients with RLS. Patients with RLS symptoms were affected not only by the difficulty of sleeping due to RLS but also by various related causes and were also found to experience very severe depressive symptoms. This information is very important to the clinician for treating patients with RLS. Interestingly, a multicenter, randomized, placebo-controlled study reported that ropinirole, which is a dopamine agonist used for treating RLS, improved depressive and RLS symptoms in patients with RLS. ${ }^{35}$ This suggests a possible close pathophysiological correlation between depressive symptoms and RLS.

Within the RLS group, we observed all 3 types of insom- 
nia including difficulty falling asleep, broken sleep, and early morning awakening, which were significantly prevalent in severe depression subgroup. Severe depression was found to be significantly associated with all types of insomnia with ${ }^{8-11}$ times the risk within the RLS group. Insomnia is comorbid with various psychiatric and physical states, and insomnia often worsens the symptoms of the psychiatric and physical state. ${ }^{22,34}$ Insomnia due to RLS and depressive symptoms may affect and worsen each other. On the other hand, severe depression may be exacerbated by the aggravation of insomnia in RLS. There was a significant difference in the number of shift workers between subgroup with and without severe depression. It is necessary to pay attention to interpretation of the results because of the relatively small number in the severe depression subgroup and lack of shift workers in the subgroup without severe depression. However, since the mood symptoms and RLS are closely related to the circadian rhythm independently, ${ }^{36-40}$ we speculated that the shift workers among patients with RLS experienced severe depressive symptoms due to an effect of the disturbed circadian rhythm. ESS total score was significantly higher, and excessive daytime sleepiness was significantly frequent in patients with severe depression compared with those without severe depression in the RLS group. This suggests that RLS comorbid with severe depression might cause excessive daytime sleepiness. Patients with depression often have insomnia or hypersomnia, and they easily feel fatigue and loss of energy, which can be expressed as excessive daytime sleepiness. ${ }^{41,42}$ RLS is associated with daytime sleepiness. ${ }^{43,44}$ Hence, we concluded that the risk of experiencing excessive daytime sleepiness was higher in patients with RLS with severe depressive symptoms than in those with RLS without severe depressive symptoms.

Within the RLS group, only RBC count among the hematological features showed a significantly lower level in patients with severe depression than those without severe depression. Although not statistically significant, the level of $\mathrm{Hb}$ tended to be lower in patients with severe depression than in those without severe depression. Hematological features were considered as the major causes of RLS, and various studies have reported the association of RLS with hematological features. ${ }^{13,45-47}$ In the present study, we also found that some of the hematological features related to RBC were associated with patients with RLS experiencing severe depressive symptoms, showing consistently low levels, although no association was found with anemia.

The present study has several limitations that are important to consider for the interpretation of the results. First, the analysis was performed on the cohort sample not designed for the study of RLS only. We could not enquire subjects about the symptoms of RLS and other variables; howev- er, we obtained the information about RLS from the previously collected cohort data. Since this cohort was originally designed for the investigation of various medical features, it might lack information about the variables that we were investigating. However, it is meaningful that this cohort is not clinic-based but community-based, especially for the investigation of comorbidity of RLS with depression. Second, almost all variables except hematological features were obtained by subjective self-reporting. It is limited information because clinicians did not investigate the patients one-on-one; however, it is difficult to investigate a large number of patients in a sample of over thousands. Instead, the 4 essential symptoms of RLS were investigated, and some systemic self-rating scales (BDI and ESS) were provided to the cohort samples. In addition, this cohort was operated with a high level of quality as a national project. ${ }^{26}$ Third, laboratory tests of hematological features used for the analysis were limited to find the association with RLS. Other important laboratory tests such as serum ferritin level, which is the most important test for evaluating the association with the pathophysiology of RLS, could not be obtained from the cohort data. As mentioned above, this study was not designed for the study of RLS; it had limited variables. However, we could obtain data on some of the hematological features and found significant findings in relation with RLS.

In summary, we found that RLS was significantly associated with depressive symptoms, especially severe depressive symptoms, when compared with the non-RLS group. Moreover, patients with RLS comorbid with severe depression showed all types of insomnia, excessive daytime sleepiness, and low RBC count. Based on these results, we suggest that mood symptoms such as depressive symptoms must be evaluated when treating patients with RLS in clinical practice. In particular, when patients with RLS experience severe depression, clinicians should treat patients focusing on insomnia and excessive daytime sleepiness and evaluate the hematological measures. When treating patients with RLS comorbid with depression, the RLS symptoms should be closely monitored because antidepressant medications could aggravate the RLS symptoms, ${ }^{48-50}$ and the clinicians should consider the prescription of dopamine agonists such as pramipexole for control of RLS symptoms. ${ }^{51}$ In the future, it would be possible to investigate the causality as well as the association between RLS and depressive mood symptoms, if the study is performed on a large number of community-based cohort samples designed for the study of RLS.

\section{Acknowledgments}

This study was provided with bio-specimens and data from the Korean Genome Analysis Project (4845-301), the Korean Genome and Epidemiology Study (4851-302), and the Korea Biobank Project (4851-307, KBP2013-000) that were supported by the Center for Disease Control and Pre- 
vention, Republic of Korea.

\section{REFERENCES}

1. Allen RP, Picchietti D, Hening WA, Trenkwalder C, Walters AS, Montplaisi J, et al. Restless legs syndrome: diagnostic criteria, special considerations, and epidemiology. A report from the restless legs syndrome diagnosis and epidemiology workshop at the National Institutes of Health. Sleep Med 2003;4:101-119.

2. Cho YW, Shin WC, Yun CH, Hong SB, Kim JH, Allen RP, et al. Epidemiology of restless legs syndrome in Korean adults. Sleep 2008;31:219223 .

3. Kim J, Choi C, Shin K, Yi H, Park M, Cho N, et al. Prevalence of restless legs syndrome and associated factors in the Korean adult population: the Korean Health and Genome Study. Psychiatry Clin Neurosci 2005;59:350-353.

4. Walters AS. Toward a better definition of the restless legs syndrome. The International Restless Legs Syndrome Study Group. Mov Disord 1995;10:634-642.

5. Trenkwalder C, Paulus W, Walters AS. The restless legs syndrome. Lancet Neurol 2005;4:465-475.

6. Winkelmann J, Schormair B, Lichtner P, Ripke S, Xiong L, Jalilzadeh S, et al. Genome-wide association study of restless legs syndrome identifies common variants in three genomic regions. Nat Genet 2007;39:10001006.

7. Stefansson H, Rye DB, Hicks A, Petursson H, Ingason A, Thorgeirsson TE, et al. A genetic risk factor for periodic limb movements in sleep. N Engl J Med 2007;357:639-647.

8. Schormair B, Kemlink D, Roeske D, Eckstein G, Xiong L, Lichtner P, et al. PTPRD (protein tyrosine phosphatase receptor type delta) is associated with restless legs syndrome. Nat Genet 2008;40:946-948.

9. Banno K, Delaive K, Walld R, Kryger MH. Restless legs syndrome in 218 patients: associated disorders. Sleep Med 2000;1:221-229.

10. Allen RP, Auerbach S, Bahrain H, Auerbach M, Earley CJ. The prevalence and impact of restless legs syndrome on patients with iron deficiency anemia. Am J Hematol 2013;88:261-264.

11. Connor JR, Boyer PJ, Menzies SL, Dellinger B, Allen RP, Ondo WG, et al. Neuropathological examination suggests impaired brain iron acquisition in restless legs syndrome. Neurology 2003;61:304-309.

12. Becker PM. The biopsychosocial effects of restless legs syndrome (RLS). Neuropsychiatr Dis Treat 2006;2:505-512.

13. Akyol A, Kiylioglu N, Kadikoylu G, Bolaman AZ, Ozgel N. Iron deficiency anemia and restless legs syndrome: is there an electrophysiological abnormality? Clin Neurol Neurosurg 2003;106:23-27.

14. Tobiasson M, Alyass B, Soderlund S, Birgegard G. High prevalence of restless legs syndrome among patients with polycytemia vera treated with venesectio. Med Oncol 2010;27:105-107.

15. Arico D, Raggi A, Siragusa M, Zucconi M, Ferri R. Restless legs syndrome as the presenting symptom of multiple myeloma. J Clin Sleep Med 2013;9:383-385.

16. Arunthari V, Kaplan J, Fredrickson PA, Lin SC, Castillo PR, Heckman MG. Prevalence of restless legs syndrome in blood donors. Mov Disord 2010;25:1451-1455.

17. Allen RP, Walters AS, Montplaisir J, Hening W, Myers A, Bell TJ, et al. Restless legs syndrome prevalence and impact: REST general population study. Arch Intern Med 2005;165:1286-1292.

18. Happe S, Reese JP, Stiasny-Kolster K, Peglau I, Mayer G, Klotsche J, et al. Assessing health-related quality of life in patients with restless legs syndrome. Sleep Med 2009;10:295-305.

19. Sevim S, Dogu O, Kaleagasi H, Aral M, Metin O, Camdeviren H. Correlation of anxiety and depression symptoms in patients with restless legs syndrome: a population based survey. J Neurol Neurosurg Psychiatry 2004;75:226-230.

20. Hornyak M. Depressive disorders in restless legs syndrome: epidemiology, pathophysiology and management. CNS Drugs 2010;24:89-98.
21. Winkelman JW, Finn L, Young T. Prevalence and correlates of restless legs syndrome symptoms in the Wisconsin Sleep Cohort. Sleep Med 2006; 7:545-552.

22. Winkelmann J, Prager M, Lieb R, Pfister H, Spiegel B, Wittchen HU, et al. "Anxietas tibiarum". Depression and anxiety disorders in patients with restless legs syndrome. J Neurol 2005;252:67-71.

23. Cuellar NG, Strumpf NE, Ratcliffe SJ. Symptoms of restless legs syndrome in older adults: outcomes on sleep quality, sleepiness, fatigue, depression, and quality of life. J Am Geriatr Soc 2007;55:1387-1392.

24. Vandeputte M, de Weerd A. Sleep disorders and depressive feelings: a global survey with the Beck depression scale. Sleep Med 2003;4:343345.

25. Yun CH, Lee SK, Kim H, Park HK, Lee SH, Kim SJ, et al. Association between irritable bowel syndrome and restless legs syndrome in the general population. J Sleep Res 2012;21:569-576.

26. Cho YS, Go MJ, Kim YJ, Heo JY, Oh JH, Ban HJ, et al. A large-scale genome-wide association study of Asian populations uncovers genetic factors influencing eight quantitative traits. Nat Genet 2009;41:527-534.

27. Ban HJ, Kim SC, Seo J, Kang HB, Choi JK. Genetic and metabolic characterization of insomnia. PLoS One 2011;6:e18455.

28. Rhee M, Lee Y, Park S, Sohn C, Chung Y, Hong S, et al. A standardization study of Beck Depression Inventory I-Korean version (K-BDI): reliability and factor analysis. Korean J Psychopathol 1995;4:77-95.

29. Lee Y, Song J. A study of the reliability and the validity of the BDI, SDS, and MMPI-D scales. Korean J Clin Psychol 1991;10:98-113.

30. Cho YW, Lee JH, Son HK, Lee SH, Shin C, Johns MW. The reliability and validity of the Korean version of the Epworth sleepiness scale. Sleep Breath 2011;15:377-384.

31. Kratz A, Pesce MA, Basner RC, Einstein AJ. Appendix: Laboratory Values of Clinical Importance. In: Longo DL, Fauci AS, Kasper DL, Editors Harrison's Principles of Internal Medicine, 18e. New York, NY: The McGraw-Hill Companies; 2012, Appendix 1, p A-1.

32. O'Keeffe ST. Secondary causes of restless legs syndrome in older people. Age Ageing 2005;34:349-352.

33. Giudice M. Drug-induced restless legs syndrome. Can Pharm J (Ott) 2009;142:41-42.

34. Benca RM, Obermeyer WH, Thisted RA, Gillin JC. Sleep and psychiatric disorders. A meta-analysis. Arch Gen Psychiatry 1992;49:651-668; discussion 669-670.

35. Benes H, Mattern W, Peglau I, Dreykluft T, Bergmann L, Hansen C, et al. Ropinirole improves depressive symptoms and restless legs syndrome severity in RLS patients: a multicentre, randomized, placebocontrolled study. J Neurol 2011;258:1046-1054.

36. Moon JH, Cho CH, Son GH, Geum D, Chung S, Kim H, et al. Advanced circadian phase in mania and delayed circadian phase in mixed mania and depression returned to normal after treatment of bipolar disorder. EBioMedicine 2016;11:285-295.

37. Cho CH, Moon JH, Yoon HK, Kang SG, Geum D, Son GH, et al. Molecular circadian rhythm shift due to bright light exposure before bedtime is related to subthreshold bipolarity. Sci Rep 2016;6:31846.

38. Jee HJ, Cho CH, Lee YJ, Choi N, An H, Lee HJ. Solar radiation increases suicide rate after adjusting for other climate factors in South Korea. Acta Psychiatr Scand 2017;135:219-227.

39. Hening WA, Walters AS, Wagner M, Rosen R, Chen V, Kim S, et al. Circadian rhythm of motor restlessness and sensory symptoms in the idiopathic restless legs syndrome. Sleep 1999;22:901-912.

40. Michaud M, Dumont M, Selmaoui B, Paquet J, Fantini ML, Montplaisir J. Circadian rhythm of restless legs syndrome: relationship with biological markers. Ann Neurol 2004;55:372-380.

41. Demyttenaere K, De Fruyt J, Stahl SM. The many faces of fatigue in major depressive disorder. Int J Neuropsychopharmacol 2005;8:93-105.

42. Fava M. Daytime sleepiness and insomnia as correlates of depression. J Clin Psychiatry 2004;65 Suppl 16:27-32.

43. Fulda S, Wetter TC. Is daytime sleepiness a neglected problem in patients with restless legs syndrome? Mov Disord 2007;22(Suppl 18):S409- 
S413.

44. Ulfberg J, Nystrom B, Carter N, Edling C. Prevalence of restless legs syndrome among men aged 18 to 64 years: an association with somatic disease and neuropsychiatric symptoms. Mov Disord 2001;16:1159-1163.

45. Ulfberg J, Nystrom B. Restless legs syndrome in blood donors. Sleep Med 2004;5:115-118.

46. Allen RP, Earley CJ. Restless legs syndrome: a review of clinical and pathophysiologic features. J Clin Neurophysiol 2001;18:128-147.

47. Prosperetti C, Manconi M. Restless Legs Syndrome/Willis-Ekbom Disease and Pregnancy. Sleep Med Clin 2015;10:323-329, xiv.

48. Nikolaou KN, Michopoulos I, Douzenis A, Papazahos C, Papageorgiou C, Gournellis R. Restless legs syndrome associated with the combined use of duloxetine plus paroxetine. J Clin Psychopharmacol 2015;35:345346.

49. Prospero-Garcia KA, Torres-Ruiz A, Ramirez-Bermudez J, VelazquezMoctezuma J, Arana-Lechuga Y, Teran-Perez G. Fluoxetine-mirtazapine interaction may induce restless legs syndrome: report of 3 cases from a clinical trial. J Clin Psychiatry 2006;67:1820.

50. Bliwise DL, Zhang RH, Kutner NG. Medications associated with restless legs syndrome: a case-control study in the US Renal Data System (USRDS). Sleep Med 2014;15:1241-1245.

51. Makiguchi A, Nishida M, Shioda K, Suda S, Nisijima K, Kato S. Mirtazapine-induced restless legs syndrome treated with pramipexole. J Neuropsychiatry Clin Neurosci 2015;27:e76. 